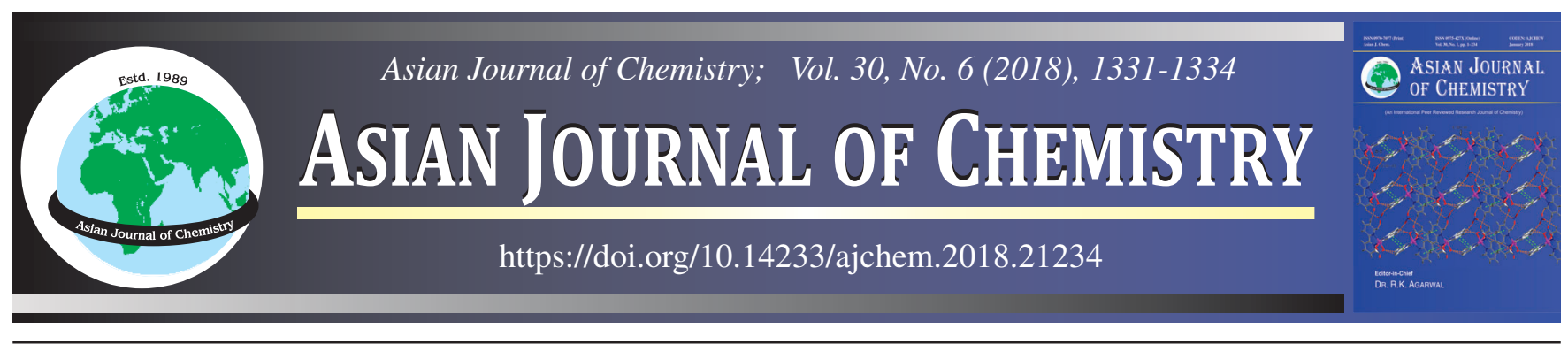

\title{
Spectrophotometric Determination of Aprepitant in Bulk and Pharmaceutical Dosage Forms Using Bromocresol Green as Chromogenic Reagent
}

\section{Effat Souri, Amin Abbasi, Massoud Amanlou and Maliheh Barazandeh Tehrani*}

Department of Medicinal Chemistry, Faculty of Pharmacy and Drug Design and Development Research Center, Tehran University of Medical Sciences, Tehran (14155-6451), Iran

*Corresponding author: Fax: +98 21 66461178; Tel: +98 21 4122230; E-mail: barazand@ sina.tums.ac.ir study a simple and accurate spectrophotometric method has been developed for quantitative determination of aprepitant in bulk and pharmaceutical dosage forms based on the formation of ion-pair complex between the drug and bromocresol green. The 1:1 yellow colour aprepitant-bromocresol green (BCG) ion-pair complex was formed in buffer solution at $\mathrm{pH}=4$, extracted with chloroform and measured at $413 \mathrm{~nm}$. The optimum reaction conditions such as $\mathrm{pH}$, reagent amount, extracting solvent and stoichiometry of the ion-pair complex | were investigated. The developed method showed excellent linearity over the concentration range of $150-500 \mu \mathrm{g} / \mathrm{mL}$ with acceptable correlation coefficient $\left(\mathrm{r}^{2}=0.998\right)$, precision $(\mathrm{CV}<3.67 \%)$ and accuracy (Error $\left.<3.46 \%\right)$. The proposed method was successfully applied for determination of aprepitant in capsule dosage forms and no interference from excipients was observed.

Keywords: Aprepitant, Bromocresol green, Ion-pair complex formation, Spectrophotometry.

\section{INTRODUCTION}

Substance $\mathrm{P}$ is the most abundant neurokinin in mammalian CNS and a potent modulator of neuroimmuno regulation $[1,2]$. Drugs which block substance P from binding to neurokinin type 1 (NK1) receptors can be of use as antiemetic agents as these neurotransmitters are implicated in the pathoetiology of emesis [3,4]. Aprepitant i.e., 5- $([(2 R, 3 S)-2-((R)-1-[3,5-b i s(\operatorname{tri}-$ fluoromethyl) phenyl]ethoxy)-3-(4-fluorophenyl)morpholino]methyl)-1H-1,2,4-triazo-1-3(2H)-one (Fig. 1), is a new class of substance P/Neurokinin1 (NK1) receptor antagonist, which is effective on both acute and delayed emesis. It is a selective high affinity antagonist of human substance P/NK1 receptor and has little or no affinity for serotonin (5-HT3), dopamine and corticosteroid receptors [5].<smiles>C[C@@H](O[C@@H]1OCCN(Cc2nc(=O)[nH][nH]2)[C@H]1c1ccc(F)cc1)c1cc(C(F)(F)F)cc(C(F)(F)F)c1</smiles>

Fig. 1. Chemical structure of aprepitant
Review of the literature reveals that few methods were developed for the determination of aprepitant either in biological fluids or pharmaceutical preparations. These methods include: LC-MS method for its determination in human plasma $[6,7]$ and RP-HPLC method for aprepitant determination in pharmaceutical dosage forms [8,9]. Although these methods offer a high degree of specificity, yet they require large amount of high purity organic solvents and highly sophisticated and dedicated instrumentation. This led us to develop a simple and sensitive spectrophotometric method for its determination in pharmaceutical preparations. Aprepitant is weakly absorbing light in the UV region and is thus subject to interference from excipients and/or impurities. Extractive spectrophotometric procedures are common for their sensitivity in the assay of drugs and, therefore, ion-pair extractive spectrophotometry using a chromogenic reagent has received considerable attention for the quantitative determination of many pharmaceutical compounds [10-13]. Bromocresol green (BCG) is a useful chromogenic reagent used for determination of amines in acidic media. The proposed method is based on the formation of ion-pair between aprepitant and bromocresol green. Several pharmaceutical compounds have been determined through this approach [14-18]. Therefore, the aim of this work is to develop a simple, sensitive and specific ion-pair spectrophotometric method for the determination of aprepitant in dosage forms. 


\section{EXPERIMENTAL}

A double beam spectrophotometer (UV-160) manufactured by Shimadzu, Japan with a fixed $2 \mathrm{~nm}$ bandwidth and quartz $1 \mathrm{~cm}$ cells were used for spectrophotometric measurements.

Waters (Milford, USA) HPLC system (Model 515 pump, Model 717 plus Autosampler and Model 486 UV-visible detector) connected to a Multi-channel Chrom \& Spec software was used for determination of aprepitant in dosage forms.

Bromocresol green (BCG), methanol, chloroform and acetonitrile (HPLC grade) was pur-chased from Merck (Darmstadt, Germany). Abitant ${ }^{\circledR}$ capsules containing $125 \mathrm{mg}$ of aprepitant were from Dr Abidi Pharmaceutical Company (Tehran, Iran).

Standard solutions: To prepare a standard solution of aprepitant, $2 \mathrm{mg}$ of drug was dissolved in $10 \mathrm{~mL}$ of distilled water. Calibration solutions in the concentration range of 150$500 \mu \mathrm{g} / \mathrm{mL}(150,200,250,275,300,325,350,400$ and 500 $\mu \mathrm{g} / \mathrm{mL})$ were prepared after appropriate dilution. To prepare the bromocresol green solution $\left(5 \times 10^{-4}\right) 349 \mathrm{mg}$ of the regent was dissolved in $1 \mathrm{~L}$ distilled water containing $2 \mathrm{~mL}$ of $1 \mathrm{M}$ $\mathrm{NaOH}$.

To prepare the $0.1 \mathrm{M}$ phosphate buffer solution, $7.8 \mathrm{~g}$ $\mathrm{KH}_{2} \mathrm{PO}_{4}$ was dissolved in $400 \mathrm{~mL}$ of distilled water and the volume brought to $500 \mathrm{~mL}$ after adjusting the $\mathrm{pH}$ value $(\mathrm{pH}$ values of 2-7).

General procedure for sample preparation: In a $100 \mathrm{~mL}$ separating funnel, $1 \mathrm{~mL}$ of standard solution of aprepitant, $2 \mathrm{~mL}$ of phosphate buffer $(\mathrm{pH} 4.0)$ and $6 \mathrm{~mL}$ of bromocresol green solution were added. Extraction was performed three times by 5, 3 and $2 \mathrm{~mL}$ of chloroform after shaking the separating funnel vigorously for $30 \mathrm{~s}$. The chloroform phase was transferred to a $10 \mathrm{~mL}$ volumetric flask after passing over anhydrous sodium sulfate. The absorbance of the solution was measured at $413 \mathrm{~nm}$ after volume completion with chloroform.

\section{Optimization of the reaction conditions}

Effect of pH: The ion-pair complex formation was performed at different $\mathrm{pH}$ values in the range of 2-7 (2, 3, 4, 5, 6 and 7 ) according to the general procedure using phosphate buffer to find out the optimum $\mathrm{pH}$ value.

Effect of reagent amount: Using different volumes $(0.5$, $1,2,3,4,5,6,7,8$ and $9 \mathrm{~mL})$ of bromocresol green reagent $(5$ $\times 10^{-4} \mathrm{M}$ ) according to the general procedure, the effect of reagent amount was studied to find out maximum ion-pair complex formation.

Selection of the extracting solvent: To find out the best extracting solvent, chloroform; dichloromethane; ethyl acetate; and diethyl ether were used as extracting solvents and the absorbance of the resulting ion-pair complexes were compared to find out the best extracting solvent.

Stoichiometry of ion-pair complex formation: The stoichiometry of complex formation was studied by using the Job's method of continuous variation. To perform this experiment, different volumes of aprepitant solution $\left(5 \times 10^{-4} \mathrm{M}\right)$ and bromocresol green solution $\left(5 \times 10^{-4} \mathrm{M}\right)$ were mixed to reach to a fixed total volume $(0: 1,1: 9,2: 8,2.5: 7.5,3.3: 6.7,5: 5$, $6.7: 3.3,7.5: 2.5,8: 2,9: 1$ and 10:0). The solutions were extracted based on the general procedure and the absorbance of the resulting solution was measured and plotted over the aprepitant mole ratio in the mixture to find out the stoichiometry of the reaction.

Application of the method for determination of aprepitant in dosage forms: The content of 10 aprepitant capsules (125 mg) were completely mixed. An amount of the powder equivalent to 1 capsule (125 mg of aprepitant) accurately weighed and dissolved in $100 \mathrm{~mL}$ of a mixture of methanol and water (80:20). After sonication, centrifugation and proper dilution, $1 \mathrm{~mL}$ of the solution was treated according to the general procedure to find out the aprepitant amount. The amount of aprepitant was also determined by HPLC using the USP/ BP standard procedure [19,20].

Relative recovery: The relative recovery of aprepitant from dosage form was evaluated by standard addition method. Aprepitant standard solution at concentration level of 250 $\mathrm{mg} / \mathrm{mL}$ was added to an equal amount of aprepitant solution obtained from capsule solution. After ion-pair complex formation according to the general procedure, the absorbance of this solution was compared with a standard solution at $250 \mathrm{mg} / \mathrm{mL}$ after subtraction of the absorbance of capsule powder. The relative recovery was then calculated.

Linearity: To find out the linearity of the proposed method, calibration solutions of aprepitant (in six series) were prepared and analyzed based on the general procedure. The calibration curves were plotted and statistical data calculated.

Precision and accuracy: To check the precision and accuracy of the method, four different concentrations of aprepitant solutions $(150,300,400$ and $500 \mathrm{mg} / \mathrm{mL})$ were prepared in triplicate. After reading the absorbance of the extracted solutions the concentration was measured using a calibration curve and the within-day precision and accuracy were calculated. This procedure was repeated for three consecutive days to find out the between-day precision and accuracy of the method.

\section{RESULTS AND DISCUSSION}

Absorption spectra: Aprepitant exhibits the UV absorption at $210 \mathrm{~nm}$. Due to the low absorption wavelength, there is a high potential for interference with excipients. Bromocresol green was chosen as a chromogenic reagent, which reacts under mild conditions with amino groups to produce an ion-pair complex. It has been utilized for the analysis of some pharmaceutical compounds containing amino groups [14-18]. Aprepitant contains both secondary and tertiary amino groups. In the present study aprepitant was found to react with anionic carboxyl group of bromocresol green in acidic medium $(\mathrm{pH}=$ 4.0) forming an ion-pair complex (Fig. 2). The ion-pair complex is soluble in organic solvents and after extraction with chloroform showed a maximum absorbance at $413 \mathrm{~nm}$, which was used for spectrophotometric measurements.

Effect of pH: The ion-pair complex formation was performed at different $\mathrm{pH}$ values. Maximum absorbance was observed at $\mathrm{pH}$ value of 4.0 using phosphate buffer (Fig. 3). Also the effect of buffer volume was studied. The optimum volume of the buffer was $2 \mathrm{~mL}$, which resulted in highest absorption intensity for a standard aprepitant solution and lowest absorption intensity for the blank solution (Fig. 4).

Effect of reagent amount: To find out the appropriate amount of the reagent for maximum ion-pair complex forma- 


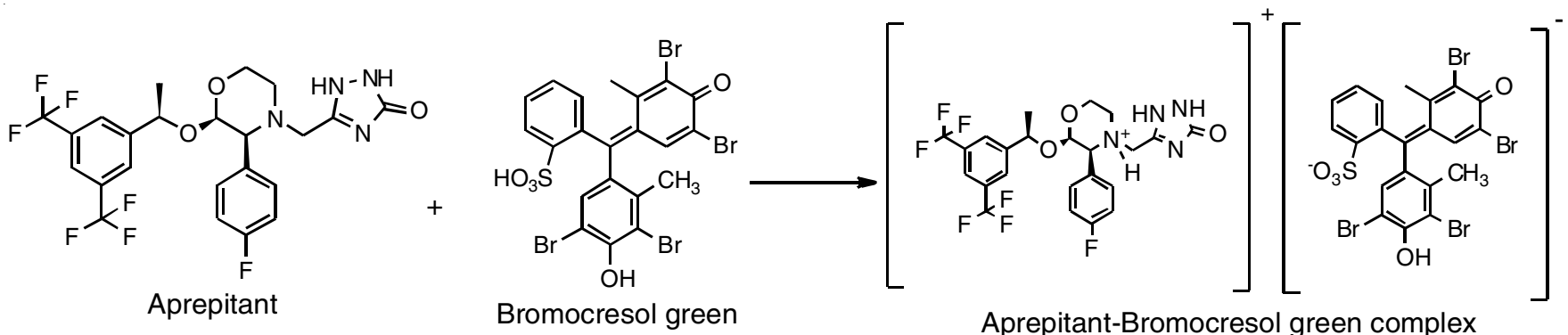

Fig. 2. Structure of the formed ion-pair complex of aprepitant and bromocresol green

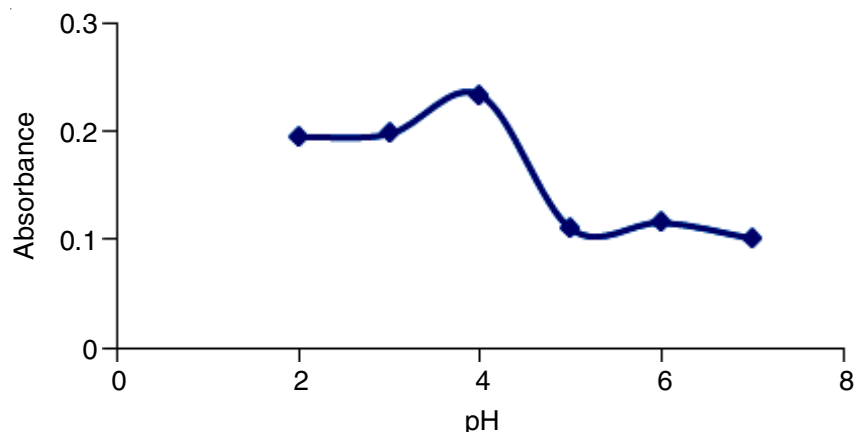

Fig. 3. Effect of $\mathrm{pH}$ of the buffer (phosphate) on the ion-pair complex formation using $1 \mathrm{~mL}$ of aprepitant $\left(5 \times 10^{-4} \mathrm{M}\right)$ and $6 \mathrm{~mL}$ of bromocresol green $\left(5 \times 10^{-4} \mathrm{M}\right)$.

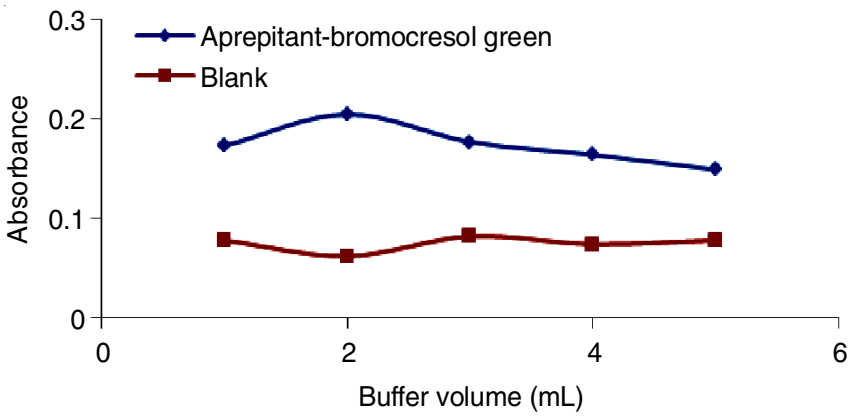

Fig. 4. Effect of the volume of the buffer (phosphate) on the ion-pair complex and reagent extraction using $1 \mathrm{~mL}$ of aprepitant $\left(5 \times 10^{-4}\right.$ M) and $6 \mathrm{~mL}$ of bromocresol green $\left(5 \times 10^{-4} \mathrm{M}\right)$

tion, different volumes of the reagent solution was used. Based on the results, by increasing the reagent volume from $0.5 \mathrm{~mL}$ to $9 \mathrm{~mL}$, the absorbance increased and become constant after addition of more reagent. So, $6 \mathrm{~mL}$ bromocresol green was chosen as the optimum volume of the reagent for ion-pair complex formation (Fig. 5).

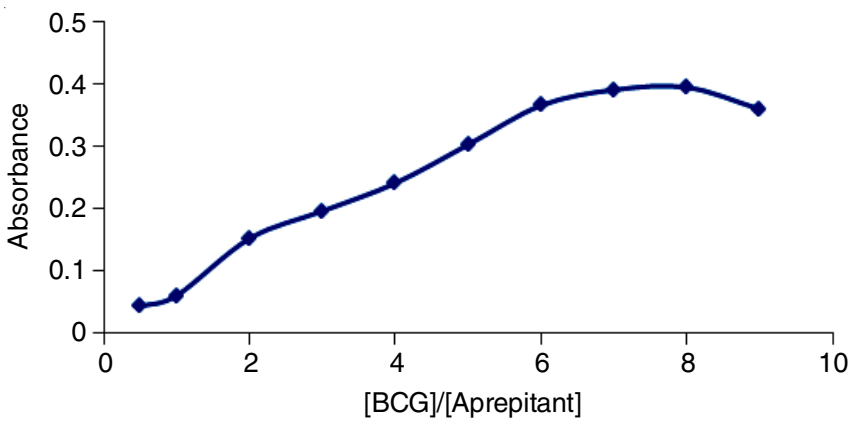

Fig. 5. Effect of bromocresol green $\left(5 \times 10^{-4} \mathrm{M}\right)$ on the absorbance of the ion-pair complex at $413 \mathrm{~nm}$ using $1 \mathrm{~mL}$ of aprepitant $\left(5 \times 10^{-4} \mathrm{M}\right)$
Stoichiometry of ion-pair complex formation: Using the Job's method of continuous variations and plotting the absorbance against the mole ratio of aprepitant, it was observed that ion-pair complex formation of aprepitant and bromocresol green is equimolar (1:1) (Fig. 6).

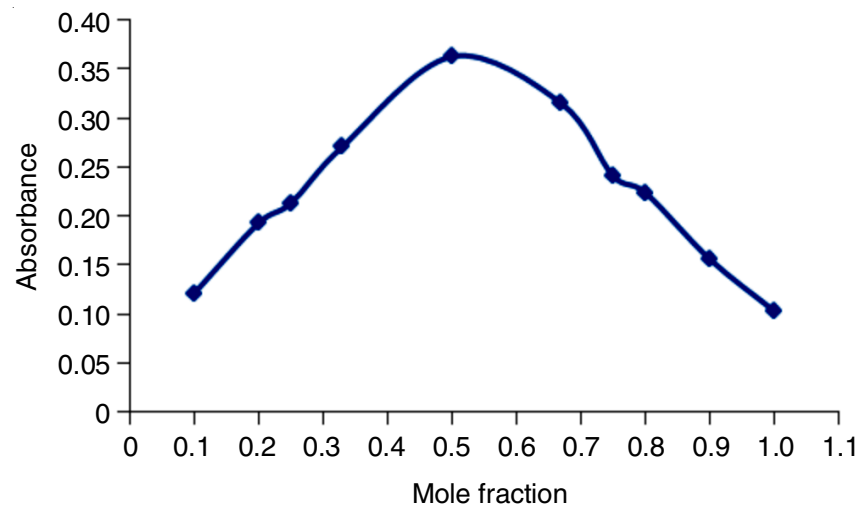

Fig. 6. Stoichiometry of the ion-pair complex of aprepitant $\left(5 \times 10^{-4} \mathrm{M}\right)$ and bromocresol green $\left(5 \times 10^{-4} \mathrm{M}\right)$ by Job's continuous variation method

Linearity: Based on the experimental method, calibration curves were constructed in the range of $150-500 \mathrm{mg} / \mathrm{mL}$. The limit of detection (LOD) and limit of quantification (LOQ) values were determined using the formula: $\mathrm{LOD}$ or $\mathrm{LOQ}=\mathrm{K}$ $\mathrm{SD} / \mathrm{b}$, where $\mathrm{K}=3$ for LOD and 10 for LOQ, SD and $\mathrm{b}$ stand for standard deviation of intercept and slope, respectively. Statistical data for six series of calibration curves are shown in Table-1.

\begin{tabular}{ll}
\multicolumn{2}{c}{ TABLE-1 } \\
\multicolumn{1}{c}{ STATISTICAL DATA OF CALIBRATION CURVES OF } \\
\multicolumn{1}{c}{ APREPITANT IN STANDARD SOLUTIONS $(\mathrm{n}=6)$} \\
\hline \multicolumn{1}{c}{ Parameters } \\
\hline \multicolumn{1}{c}{ Aprepitant } \\
\hline Wavelength $(\mathrm{nm})$ & 413 \\
Linearity $(\mu \mathrm{g} / \mathrm{mL})$ & $150-500$ \\
Regression equation & $\mathrm{Y}=0.0003561 \mathrm{X}+0.06254$ \\
SD of slope & $4.62 \times 10^{-6}$ \\
RSD of slope $(\%)$ & 1.30 \\
SD of intercept & 0.0044 \\
Correlation coefficient $\left(\mathrm{r}^{2} \pm \mathrm{SD}\right)$ & $0.9979 \pm 0.0017$ \\
LOD $(\mu \mathrm{g} / \mathrm{mL})$ & 36.60 \\
LOQ $(\mu \mathrm{g} / \mathrm{mL})$ & 122.00 \\
\hline
\end{tabular}

Precision and accuracy: Selected concentrations of aprepitant in the calibration range were used to find out the intra-day and inter-day precision and accuracy. The precision expressed as CV \% values and accuracy are shown in Table-2. 


\begin{tabular}{|c|c|c|c|c|c|c|}
\hline \multirow{3}{*}{$\begin{array}{l}\text { Concentration } \\
\text { added }(\mu \mathrm{g} / \mathrm{mL})\end{array}$} & \multicolumn{5}{|c|}{$\begin{array}{l}\text { TABLE-2 } \\
\text { PRECISION AND ACCURACY OF THE METHOD FOR DETERMINATION OF } \\
\text { APREPITANT IN STANDARD SOLUTIONS ( } \mathrm{n}=9 ; 3 \text { SETS FOR } 3 \text { DAYS })\end{array}$} & \\
\hline & \multicolumn{3}{|c|}{ Intra-day $(\mathrm{n}=3)$} & \multicolumn{3}{|c|}{ Inter-day $(n=9)$} \\
\hline & Found $(\mu \mathrm{g} / \mathrm{mL}) \pm \mathrm{SD}$ & $\mathrm{CV}(\%)$ & Error $(\%)$ & Found $(\mu \mathrm{g} / \mathrm{mL}) \pm \mathrm{SD}$ & $\mathrm{CV}(\%)$ & Error $(\%)$ \\
\hline 150 & $144.80 \pm 0.70$ & 0.48 & -3.46 & $150.56 \pm 5.53$ & 3.67 & 0.38 \\
\hline 300 & $302.43 \pm 2.11$ & 0.70 & 0.81 & $301.84 \pm 2.30$ & 0.76 & 0.61 \\
\hline 400 & $394.67 \pm 3.03$ & 0.77 & -1.33 & $399.07 \pm 6.48$ & 1.62 & -0.29 \\
\hline 500 & $499.28 \pm 5.06$ & 1.01 & -0.14 & $501.57 \pm 5.20$ & 1.04 & 0.31 \\
\hline
\end{tabular}

\begin{tabular}{|c|c|c|c|c|c|c|c|}
\hline \multirow{3}{*}{ Compound } & \multicolumn{6}{|c|}{$\begin{array}{l}\text { TABLE-3 } \\
\text { COMPARISON OF THE DEVELOPED METHOD WITH THE REFERENCE METHOD FOR } \\
\text { THE DETERMINATION OF APREPITANT CAPSULES }\end{array}$} & \\
\hline & \multirow{2}{*}{$\begin{array}{l}\text { Label claimed } \\
\quad(\mathrm{mg})\end{array}$} & \multicolumn{4}{|c|}{ Found $($ mean $\pm \mathrm{SD})$} & \multicolumn{2}{|c|}{ Statistical tests* } \\
\hline & & Proposed method & Recovery (\%) & HPLC method & Recovery (\%) & T-test & F-test \\
\hline Aprepitant & 125 & $124.73 \pm 1.76$ & $99.78 \pm 0.59$ & $124.22 \pm 0.60$ & $99.38 \pm 0.59$ & 0.211 & 0.557 \\
\hline
\end{tabular}

The data proved the good precision and accuracy of the developed method.

Application of the proposed method: The proposed spectrophotometric method was used for the determination of aprepitant in commercial capsule dosage forms. The obtained results were compared with the USP standard method. Statistical analysis of the results obtained by the reference HPLC method and the proposed spectrophotometric method performed using the Student's t-test and the Variance ratio F-test. The calculated values did not exceed the theoretical ones, indicating no significant difference between the compared methods (Table-3). The obtained relative recovery calculated by using standard addition method, $102.72 \pm 0.5 \%$, (102.30-103.35 $\%$ ) indicated that there is no interference from the excipients in capsules.

\section{Conclusion}

In this study, a spectrophotomertic method based on ionpair complex formation of aprepitant and bromocresol green was used for the determination of aprepitant. This method is simple and rapid and also cost effective. Because of the acceptable precision and accuracy of the method, it could be a useful method for routine quality control assay of aprepitant in raw material and also dosage forms without any special sample pretreatment.

\section{ACKNOWLEDGEMENTS}

This study was part of a Pharm.D. thesis supported by Tehran University of Medical Sciences.

\section{REFERENCES}

1. J. Liu, M. Zou, H. Piao, Y. Liu, B. Tang, Y. Gao, N. Ma and G. Cheng, Molecules, 20, 11345 (2015);

https://doi.org/10.3390/molecules200611345.
2. P.R. Bhandari, J. Adv. Pharm. Technol. Res., 3, 202 (2012); https://doi.org/10.4103/2231-4040.104710.

3. C.N. Rittenberg, Clin. J. Oncol. Nurs., 6, 103 (2002); https://doi.org/10.1188/02.CJON.103-104.

4. C. Girish and S. Manikandan, Indian J. Cancer, 44, 25 (2007); https://doi.org/10.4103/0019-509X.31164.

5. L.A. Sorbera, J. Castaner, M. Bayes and J. Silvestre, J. Drugs Future, 27, 211 (2002); https://doi.org/10.1358/dof.2002.027.03.661047.

6. P.V.D.L.S. Ravi Prakash, J. Bioequiv. Bioavailab., 5, 110 (2013); https://doi.org/10.4172/jbb.1000143.

7. D. Wu, D.J. Paul, X. Zhao, S.D. Douglas and J.S. Barrett, J. Pharm. Biomed. Anal., 49, 739 (2009); https://doi.org/10.1016/j.jpba.2008.12.005.

8. I.A. Darwish, I.H. Refaat, H.F. Askal and M.A. Marzouq, J. AOAC Int., 89, 334 (2006).

9. K.K. Chaitanya, D.G. Sankar, D.S. Israel and Ch. Narasimha Kumar, Der. Pharma Chemica, 5, 39 (2013).

10. V.K. Kumar, N.A. Raju and S.H. Begum, Res. J. Pharm. Technol., 2, 412 (2009).

11. A. Levent and Z. Senturk, Comb. Chem. High Throughput Screen., 13, 675 (2010); https://doi.org/10.2174/138620710791920383.

12. M.N. Patel, B.S. Bhatt, D.S. Gandhi, P.A. Dosi and P.A. Parmar, J. Anal. Chem., 67, 655 (2012); https://doi.org/10.1134/S1061934812050103.

13. D.R. Chaple and K.P. Bhusari, Asian J. Chem., 22, 2593 (2010).

14. E. Souri, D. Hemmatianpour, M. Amanlou and M.B. Tehrani, Res. J. Pharm. Biol. Chem. Sci., 5, 373 (2014).

15. M. Amanlou, A.G. Moghadam, M.B. Tehrani and E. Souri, Iran. J. Pharm. Res., 13, 81 (2014).

16. M. Amanlou, M.H. Nazlou, H. Azizian, E. Souri and H. Farsam, Anal. Lett., 40, 3267 (2007); https://doi.org/10.1080/00032710701672384.

17. E. Souri, A. Kaboodari, N. Adib and M. Amanlou, Daru, 21, 12 (2013); https://doi.org/10.1186/2008-2231-21-12.

18. A. Al-Haj Sakur and H. Fael, Int. J. Acad. Sci. Res., 4, 9 (2016).

19. USP 29 NF 24, United States Pharmacopoeia. U.S. Pharmacopeial Convention, Inc., Rockville, MD (2006).

20. BP 2003, British Pharmacopoeia. The Stationary Office under License from the Controller of Her Majesty's Stationary Office, UK, vol. I and II (2003). 